\title{
On the genetics of hypodontia and microdontia: synergism or allelism of major genes in a family with six affected members
}

\author{
S P Lyngstadaas, H Nordbø, T Gedde-Dahl Jr, P S Thrane
}

Laboratory for

Molecular Biology,

Department of Oral Pathology,

Faculty of Dentistry,

University of Oslo,

PO Box 1109,

Blindern,

N-0317 Oslo, Norway

S P Lyngstadaas

P S Thrane

Department of

Preclinical

Techniques, Dental

Faculty,

University of Oslo,

PO Box 1109,

Blindern,

N-0317 Oslo, Norway

H Nordbø

Institute of Forensic Medicine and

Department of

Dermatology,

Rikshospitalet,

Medical Faculty,

University of Oslo,

N-0027 Oslo, Norway

T Gedde-Dahl Jr

Department of

Pathology,

The Norwegian

Radium Hospital,

Montebello,

N-0310 Oslo, Norway

P S Thrane

Correspondence to:

Dr Lyngstadaas.

Received 28 June 1995

Revised version accepted for

publication 12 October 1995

\begin{abstract}
Familial severe hypodontia of the permanent dentition is a rare condition. The genetics of this entity remains unclear and several modes of inheritance have been suggested. We report here an increase in the number of congenitally missing teeth after the mating of affected subjects from two unrelated Norwegian families. This condition may be the result of allelic mutations at a single gene locus. Alternatively, incompletely penetrant non-allelic genes may show a synergistic effect as expected for a multifactorial trait with interacting gene products. This and similar kindreds may allow identification of genes involved in growth and differentiation of dental tissues by linkage and haplotype association analysis. Brittle nails, delayed growth of the hair, and delayed teething in the probands support the grouping of these conditions among the ectodermal dysplasias. ( $f$ Med Genet 1996;33:137-142)
\end{abstract}

Key words: brittle nails; brittle hair; ectodermal dysplasia; familial hypodontia.

Hypodontia is interesting to the human geneticist because it constitutes one of the most widespread polymorphisms in man. ${ }^{1}$ Few dental traits have commanded more attention among the general population and the dental profession than hypodontia. ${ }^{2}$ The mechanisms underlying hypodontia remain obscure. Congenitally missing teeth tend to run in families. ${ }^{3}$ Some investigators consider hypodontia to be the result of a single dominant gene. The classicial family study of hypodontia was performed by Grahnén ${ }^{4}$ on parents and sibs of 171 affected persons. He concluded that, in the majority of cases, hypodontia is mainly determined by a dominant autosomal gene pattern with incomplete penetrance and variable expressivity. Other studies suggest autosomal recessive and sex linked inheritance patterns ${ }^{5}$ or favour a polygenic hypothesis. ${ }^{6}$

In a review on the inheritance patterns of congenital absence of teeth, Graber ${ }^{2}$ concluded that severe hypodontia is a result of defects in a closely linked polygenic system that regulates the timing and spatial development of dental tissues, most often transmitted in an autosomal dominant pattern with incomplete penetrance and variable expressivity.

There are indications that different types of hypodontia may be caused by different genetic and epigenetic factors. ${ }^{7}$ In a large study of tooth number and size in British schoolchildren, excluding patients with more widespread abnormalities, Brook ${ }^{3}$ favoured a multifactorial model with a continuous spectrum, related to tooth number and size, with thresholds, and where position on the scale depends upon the combination of numerous genetic and environmental factors, each with a small effect. In this study the proportion of affected relatives varied with the severity of the condition in the probands and an association between hypodontia and microdontia was noted.

Other causes of hypodontia have been suggested and include an evolutionary trend towards fewer teeth, ${ }^{28}$ infections during pregnancy and early childhood, hormonal dysfunction, which itself may be inherited, and various environmental factors. ${ }^{7}$

There are indications that different genetic mechanisms control the development of permanent succedaneous and molar teeth. ${ }^{9}$ The permanent molars result from a posterior growth of the dental lamina in the last months of fetal life continuing into the first years after birth. The succedaneous tooth buds, on the other hand, are formed concomitantly with the primary dentition in early fetal life, but further development is arrested until birth. ${ }^{1011}$ The mode and site of gene action are also unknown. Animal studies have suggested that hypodontia arises when the cell mass of an undeveloped tooth germ falls below a critical size. ${ }^{12}$ Teeth are typical examples of organs developing from epithelial and mesenchymal tissues. Their growth and morphogenesis are regulated by a number of growth factor genes expressed in these two tissue components. ${ }^{13}$ Therefore, aberrations in one or more of these basic genes regulating epithelial-mesenchymal interactions during the growth of teeth could play important roles in hypodontia.

Severe hypodontia is most often observed in association with certain inherited disorders and syndromes such as cherubism (familial fibrous dysplasia of the jaw), ${ }^{14}$ Kallin syndrome, ${ }^{1516}$ incontinentia pigmenti, ${ }^{17}$ and the ectodermal dysplasias (ED). ${ }^{18-20}$ Occasionally, hypodontia is observed in persons with no other external signs of hereditary disease. Such "non-syndromic" dental agenesis is seldom an isolated phenomenon; rather it appears to be linked to other dental changes such as microdontia and reduced crown size of the remaining teeth, ${ }^{321}$ taurodontism, ${ }^{22}$ and the overal rate of dental development. ${ }^{63}$ In a study on 167 patients 


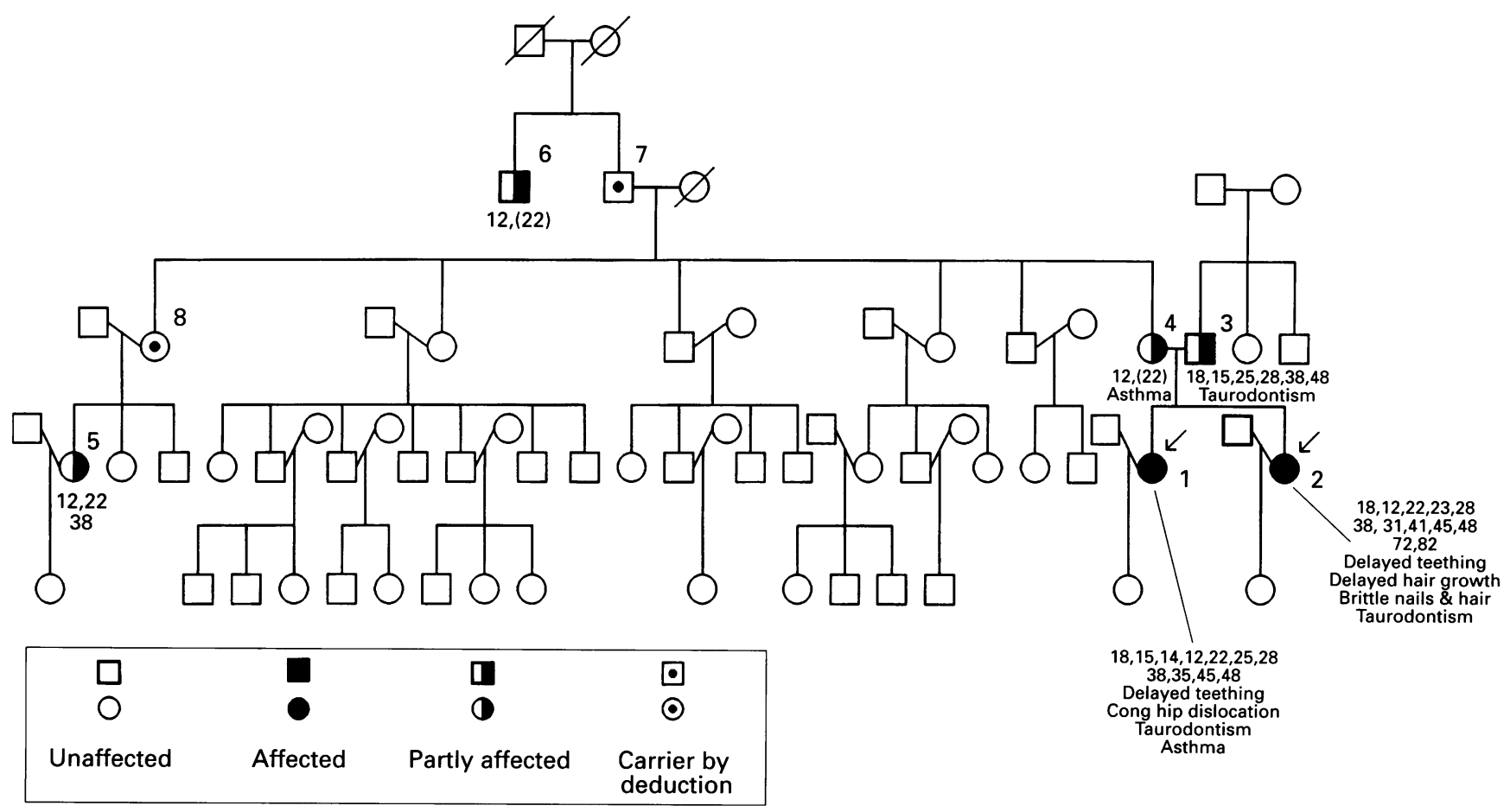

Figure 1 Pedigree of the family in which six cases of hypodontia and microdontia were found. Note the aggravation of the conditon after mating of two differently affected persons. The probands, marked with arrows, also have other ectodermal symptoms. Symptoms are given under each affected subject.

with hypodontia and 135 healthy controls, Schalk-van der Weide et $a l^{24}$ found no clear associations between congenitally missing teeth and other ectodermal symptoms. However, they concluded that if the number of missing teeth is large or if the most stable teeth, that is, the maxillary central incisors and the first molars, are missing, the patient should be examined carefully for symptoms of ectodermal dysplasia.

We present here a Norwegian family where hypodontia was aggravated after the mating of unrelated affected subjects. The probands also have other ectodermal signs. The inheritance of this particular condition and a putative association with ectodermal dysplasia are discussed.

\section{Materials, methods, and results FAMILY HISTORY}

The families, both white Norwegian, are not related, and appear normal, both physically, mentally, and socially. All members of the families receive regular dental care by private dentists.

The families, consisting of 50 people in four generations (fig 1), were asked to fill in questionnaires and agreed to make their dental records available through their private dentists. All family members, except the youngest proband, had developed normal primary dentition, but six cases of congenitally missing permanent teeth were reported. Except for the conditions observed in the probands, no other signs of hereditary disorders were reported in these families. The probands, two sisters, were referred to the Dental Hospital, University of Oslo for evaluation and treatment of severe hypodontia of their permanent dentition. They are the only children of parents who also exhibit congenitally missing permanent teeth. Their mother has two other affected relatives, an uncle and a niece, but there are no other known cases in the family of the father (fig 1).

The probands, their parents, and their children as well as their affected relatives were examined clinically and radiographically at the Dental Hospital, University of Oslo.

\section{CLINICAL INFORMATION (TABLE) \\ Probands}

Case 1, the older sister, was examined in 1970 , aged 8 years, and again in 1993, aged 31 years. Bilateral congenital hip dislocation was corrected surgically in early childhood, and she had experienced an asthmatic condition. Onset of her scalp hair growth was within the normal range. Her scalp hair is abundant and blonde, with a colour not differing conspicuously from that of her unaffected relatives. She has no current symptoms in her skin, hair, nails, eyebrows, sweat secretion, tear secretion, eyes, or hearing. Her facies and maxillomandibular relationship are normal.

Both oral examinations showed a mixed dentition with primary as well as permanent teeth present. The morphology of both primary and permanent teeth appeared normal, but when compared to the mean values reported for white populations $^{10}$ a significantly reduced mesiodistal diameter of the crowns of $11(6.8 \mathrm{~mm})$, $21(6.5 \mathrm{~mm})$, and $23(6.1 \mathrm{~mm})$ was noted. Eruption of the succedaneous teeth is severely delayed (fig 2a). No visible malformations or aberrations in other oral tissues were found.

Radiographic examination showed that she was congenitally missing 11 permanent teeth: five succedaneous maxillary teeth $(15,14,12$, 22 , and 25), two succedaneous mandibular teeth ( 35 and 45), and all four third molars 
Mating of cases 3 and 4 causes aggravation of the condition in their offspring. Both the parents' conditions are expressed in the probands, and the penetrance and expressivity of the genes involved are accentuated when they are simultaneously present. Different phenotypic appearances in the parents suggest that the condition in the offspring is a result of two different allelic mutations at a single gene locus. Alternatively, incompletely penetrant non-allelic genes may show a synergistic effect as expected in a multifactorial trait with interacting gene products. In this particular pedigree they behave then as "major" genes

\begin{tabular}{|c|c|c|c|c|c|c|c|c|}
\hline \multirow{2}{*}{$\frac{\text { Cases }}{\text { Case } 3 \text { father }}$} & \multicolumn{7}{|c|}{ Missing or (microdont) teeth } & \multirow{3}{*}{$\begin{array}{l}\text { Other symptoms } \\
\text { Taurodontism }\end{array}$} \\
\hline & 18 & 15 & & & & 25 & 28 & \\
\hline & \multicolumn{4}{|l|}{48} & & & \multirow[t]{2}{*}{38} & \\
\hline Case 4 mother & & & & 12 & $(22$ & & & Asthma \\
\hline \multirow[t]{2}{*}{ Case 1 older proband } & 18 & 15 & 14 & 12 & 12 & 25 & 28 & \multirow{2}{*}{$\begin{array}{l}\text { Reduced tooth crown sizes, delayed } \\
\text { teething, taurodontism, cong hip } \\
\text { dislocation, asthma }\end{array}$} \\
\hline & 48 & 45 & & & & 35 & 38 & \\
\hline \multirow[t]{2}{*}{ Case 2 younger proband } & 18 & & & 12 & 22 & 23 & 28 & \multirow{2}{*}{$\begin{array}{l}\text { Reduced tooth crown sizes, delayed } \\
\text { teething, taurodontism, delayed } \\
\text { hair growth, brittle nails and hair }\end{array}$} \\
\hline & 48 & 45 & & $82^{41}$ & 31 & & 38 & \\
\hline
\end{tabular}

$(18,28,38$, and 48$)$. Furthermore, $16,17,26$, 27 , and probably 36 and 46 are taurodont in form. Other osseous mandibular and maxillary structures appear normal (fig $2 \mathrm{a}$ ).

Case 2, the younger sister, was first examined in 1972 , also aged 8 years. She was re-examined in 1993 when she was aged 29. She reported that the onset of growth of the hair on her scalp was delayed until she was more than 3 years old, and that her nails always have been very brittle. She has no current symptoms in the
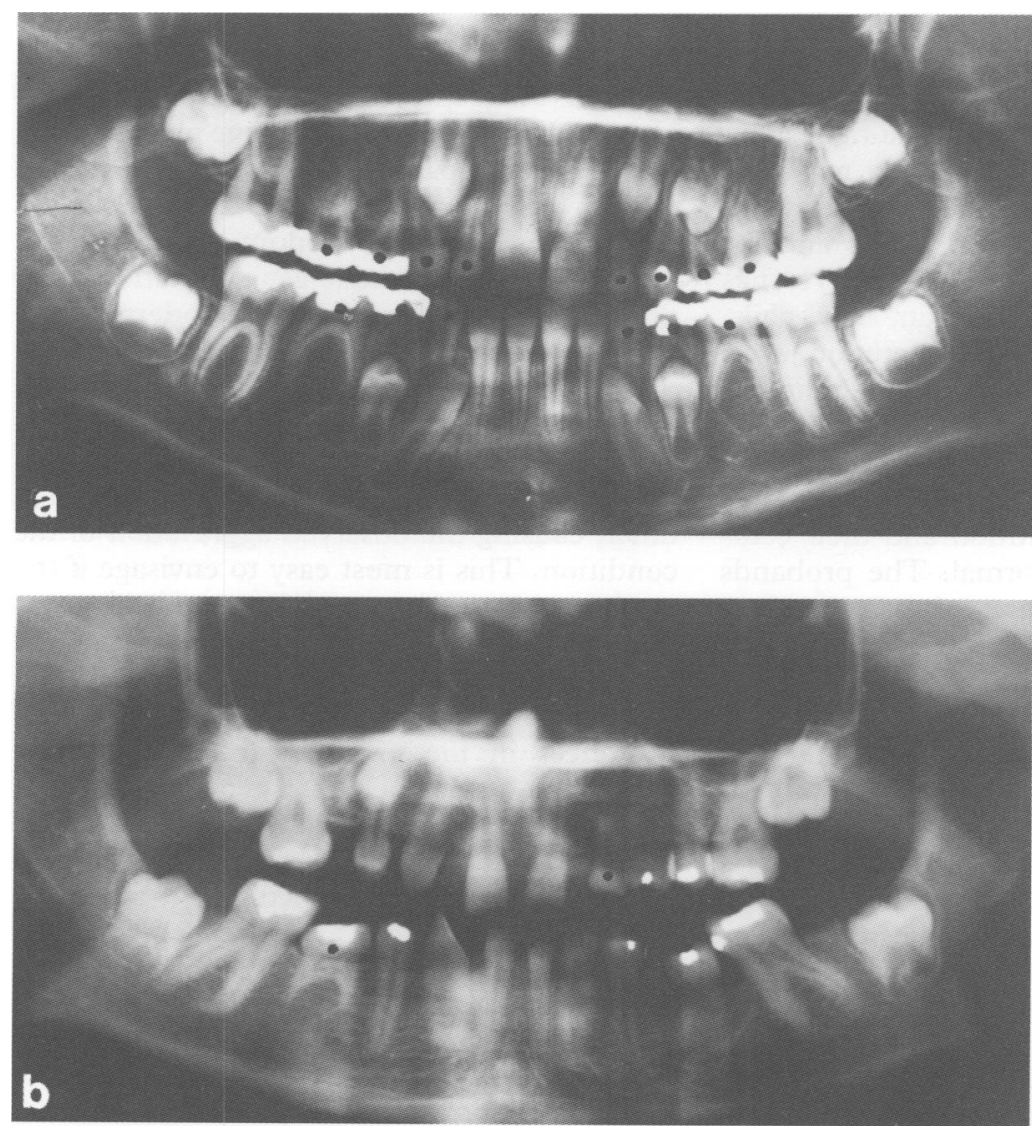

Figure 2 (a) Panoramic $x$ ray of case 1 , aged $12 \frac{1}{2}$ years, showing dental agenesis of 11 permanent teeth. Tooth eruption is delayed, the canines, premolars, and second molars have not yet started to erupt. (b) Panoramic $x$ ray of case 2 , aged 16 years, showing dental agenesis of 10 permanent teeth. The upper right second premolar (15), is impacted: Tooth eruption is severely delayed; the second molars have still not erupted at this late age. Both cases show a reduction in the size of some of the succedaneous tooth crowns. Deciduous teeth are marked. skin, eyebrows, sweat secretion, tear secretion, eyes, or hearing. Her facies and maxillomandibular relationship are normal.

Both oral examinations showed a mixed dentition with primary as well as permanent teeth present. As in her sister, the tooth morphology appeared normal, but a significantly reduced mesiodistal diameter of the crowns of 14 $(5.5 \mathrm{~mm}), 13(6.1 \mathrm{~mm}), 11(6.3 \mathrm{~mm}), 21$ $(6.1 \mathrm{~mm}), 24 \quad(5.4 \mathrm{~mm}), 34(5.6 \mathrm{~mm}), 33$ $(5.5 \mathrm{~mm}), 32(4.1 \mathrm{~mm}), 42(4.3 \mathrm{~mm}), 43$ $(5.4 \mathrm{~mm})$, and $44(5.5 \mathrm{~mm})$ was noted. Her tooth eruption was severely delayed; her second molars were still not visible when she was 16 years old (fig 2b). She also reported that her primary dentition missed two mandibular incisors, probably 72 and 82 . Two primary mandibular incisors resembling 71 and 81 were present at the first examination. Other oral tissues appeared normal.

Aged 29 she displays abundant and normal looking scalp hair, although she states that her hair is slow growing and quite brittle. Her hair is blonde with a colour not differing conspicuously from that of her relatives. Her nails are still very brittle, she cuts them rarely and must apply cosmetics to keep them intact. She exhibits no manifestation of infectious nail diseases, her blood values are within normal limits, and intensive vitamin $\mathrm{B}$, iron, and calcium treatment have had virtually no effect.

Radiographic examinations showed that she is congenitally missing 10 permanent teeth: three succedaneous maxillary teeth $(12,22$, and 23) and three succedaneous mandibular teeth $(31,41$, and 45). All four third molars $(18,28,38$, and 48$)$ are also missing. Furthermore, 16, 17, 26, 27, and probably 36 and 46 are taurodont in form and 15 is impacted. Other osseous mandibular and maxillary structures appear normal (fig 2b). Aged 7 years, $x$ rays of her mandibular incisor region showed that 32 and 42 were located and erupting distal to the two deciduous incisors present, supporting the assumption that the missing deciduous teeth were actually 72 and 82 . Unfortunately, there are no $x$ rays that might confirm the early location of the tooth buds. 
SECONDARY CASES

Case 3 is the probands' father. He has agenesis of two maxillary second premolars (15 and 25) and all four third molars $(18,28,38$, and 48). Furthermore, 16 and 26 and probably 17 and 27 are taurodont in form. His maxillary lateral incisors 12 and 22 appear normal, but his left maxillary canine is impacted. The size of his teeth are all within normal limits. He has no current symptoms in the skin, hair, nails, eyebrows, sweat secretion, tear secretion, eyes or hearing. His facies and maxillomandibular relationship are normal.

Case 4 is the probands' mother. She has agenesis of the right maxillary lateral incisor (12) and her left lateral incisor (22) is small and peg shaped. She has developed a full set of third molars. There are no signs of taurodontism and her tooth sizes are within normal limits. She reports a mild asthmatic condition. She has no current symptoms in the skin, hair, nails, eyebrows, sweat secretion, tear secretion, eyes, or hearing. Her facies and maxillomandibular relationship are normal.

Case 5 is a female cousin of the probands. She is congenitally missing both maxillary lateral incisors (12 and 22) and her left mandibular third molar (38). There are no signs of taurodontism and her tooth sizes are within normal limits. She has no current symptoms in the skin, hair, nails, eyebrows, sweat secretion, tear secretion, eyes, or hearing. Her facies and maxillomandibular relationship are normal.

Case 6 is an uncle of the probands' mother. His dentition shows agenesis of the right maxillary lateral incisor (12) and his left maxillary lateral incisor (22) is small and peg shaped. There are no signs of taurodontism and his tooth sizes are within normal limits. $\mathrm{He}$ has no current symptoms in the skin, hair, nails, eyebrows, sweat secretion, tear secretion, eyes, or hearing. His facies and maxillomandibular relationship are normal.

The probands' grandfather (case 7) and an aunt (case 8) are carriers by deduction. They both exhibit normal dentition and their ectodermal tissues appear normal. The probands each have one child. Case 1 has a daughter born in 1992 and case 2 has a daughter born in 1994. Neither of these children show any signs of missing primary teeth or any other ectodermal developmental defects so far.

\section{SCANNING ELECTRON MICROSCOPY}

Hair from the probands and their parents was viewed in a Phillips 5515 scanning electron microscope (SEM) equipped with an $\mathrm{EDAX}^{\circledR}$ 9900 energy dispersive $x$ ray analyser. The hair samples were layered with an ultrathin layer of carbon and analysed to detect the quantities of elements present. Hair from three people not related to the probands was analysed as controls. The ultrastructure and composition of the hair from the probands did not differ significantly from the controls, although the hair shafts from the youngest sister (case 2) had a somewhat smaller diameter than the other samples examined. No longitudinal depressions, loss of cuticle cells, or exposed cortex fibres consistent with the findings in $\mathrm{X}$ linked $\mathrm{ED}^{25}$ and hidrotic $\mathrm{ED}^{26}$ were found.

\section{Discussion}

The probands' father shows agenesis of the teeth in the premolar and molar area. The inheritance pattern of his condition remains uncertain because of the small number of members and affected persons in this family, but that both daughters have inherited the condition is consistent with a dominant mode of inheritance. The probands' mother exhibits only frontal agenesis of the permanent teeth, and this is also the case for the other affected persons in her family. Her condition appears to be an autosomal one, affecting both sexes, involving a gene with incomplete penetrance and variable expressivity.

Since different segments of the jaw are affected differently in the conditions of the mother and the father, it is likely that they constitute two phenotypic variants of hypodontia.

The probands have a condition considerably more severe than the mere sum of their parents' anomalies. The most straightforward explanation for this is that the parents are heterozygous and both affected daughters are homozygous for mutations at a single predisposing gene locus and are thus more severely affected. Also, the other ectodermal findings in the daughters suggest a dosage phenomenon since neither parent is affected. This explanation is also consistent with the observation that the most severe hypodontias are reported in association with single gene conditions, like the two X linked hypohidrotic ectodermal dysplasias $^{20}$ and incontinentia pigmenti. ${ }^{17}$

The different phenotypic appearance in the parents, on the other hand, suggests two different mutations. In this family these mutations then mutually influence the penetrance of each other, causing the observed aggravation of the condition. This is most easy to envisage if the predisposing genes are different allelic mutations at the same gene locus. In this way both the dosage phenomenon observed in the daughters and the different phenotypic appearances in the parents can be explained. Mutations at two separate gene loci cannot, however, be excluded if they show an epigenetic effect on each other as part of a multifactorial system. In this particular pedigree they behave then as "major" genes. The younger daughter exhibits teeth (for example, 15 and 25) that are missing in her father. This, and the fact that the daughters are differently affected by the condition, suggests a trait with incomplete penetrance and variable expressivity.

The observed taurodont teeth and reduction in tooth crown sizes in the probands are known associations with hypodontia, ${ }^{322}$ and suggest that the underlying mechanisms of this particular condition affect tooth development at several stages. 
The presence of permanent teeth corresponding to the apparently missing deciduous mandibular incisors in case 2 is not easily explained. Clinically and radiographically this seems to be the case, but it is not consistent with current understanding of succadaneous tooth development, since these teeth develop from the same epithelial structures that form the deciduous tooth germs. The most likely explanation for this observation is therefore that the eruption positions of the succadaneous incisors are altered owing to the missing deciduous teeth, and that both primary and permanent mandibular incisors originate from the same early tooth germs. If this is not the case, then different mechanisms must underlie the growth of primary and succadaneous teeth. Studies on epithelial-mesenchymal signalling ${ }^{2728}$ and the establishment of a new method for restricted "knock out" of gene expression ${ }^{29}$ have recently confirmed the role of several genes in tooth development that may be involved in such mechanisms.

Severe dental aberrations, like those seen in the probands, are seldom a separate entity. Several authors have suggested that hypodontia is a "microform" of ED. ${ }^{2}$ Recently, 155 different variants of ED were reported by Pinheiro and Freire-Maia. ${ }^{30}$ Since dentists have little experience with diseases and malformations in extraoral tissues and their examinations are limited to the mouth and teeth, other symptoms of ED may escape their attention. ${ }^{24}$ Because of this, mild ectodermal dysplasias with oral manifestions may be under-reported entities. Besides aberrations in the permanent dentition, the probands in this study also exhibit agenesis of the primary dentition, delayed teething, hair and nail dysgenesis, bilateral congenital hip dislocation, and an asthmatic condition. Hypodontia and hip dislocation are frequently reported in focal dermal hypoplasias, ${ }^{31}$ whereas hypodontia and asthmathic conditions are well known associations with the hypohidrotic ectodermal dysplasias. ${ }^{32} \mathrm{~A}$ similar case of hypodontia in two sisters has also been decribed associated with an autosomal recessive localised epidermolysis bullosa simplex and named Kallin syndrome. ${ }^{1516}$ Also the Kallin gene mutation may have some penetrance in the heterozygous state since both the otherwise healthy parents of the Kallin sisters lacked their third molars. Our probands, however, did not show any extraoral manifestations of localised EB simplex, incontinentia pigmenti, focal dermal hypoplasia, or cherubism. Neither were we able to confirm a diagnosis of ED based on SEM examination of the hair. However, the clinical findings in the probands are consistent with the ectodermal dysplasias. We therefore propose to include this condition in the group of ED diseases, possibly within the tricho-odontoonychial subgroup.

\section{Conclusion}

The probands in this study suffer from inherited severe hypodontia affecting both succedaneous teeth and permanent molars. Taurodontism, reduced tooth crown sizes, and missing primary teeth are other oral manifestations. The trait seems to be a dominant one with incomplete penetrance and variable expressivity, being aggravated when the genes involved are concomitantly expressed. Different phenotypic appearances in the parents suggest that the condition in the offspring is a result of two different allelic mutations at a single gene locus. Alternatively, incompletely penetrant non-allelic genes may show a synergistic effect, as expected in a multifactorial trait with interacting gene products. In this particular pedigree they behave then as "major" genes.

Other ectodermal findings in the probands are consistent with the ectodermal dysplasias. We therefore propose to include this condition in the group of ED diseases.

1 von Wowern N. Cherubism. Int $\mathcal{F}$ Oral Surg 1972;1:240-9.

2 Graber LW. Congenital absence of teeth: a review with emphasis on inheritance patterns. f Am Dent Assoc 1978; 96:266-75.

3 Brook AH. A unifying aetiological explanation for anomalies of human tooth number and size. Arch Oral Biol 1984;29: 373-8.

4 Grahnén H. Hypodontia in the permanent dentition. A clinical and genetical investigation. Odontol Rev 1956;7:

5 Burzynski NJ, Escobar VH. Classification and genetics of numeric anomalies of dentition. Birth Defects 1983;19. 95-106.

6 Suarez BK, Spence MA. The genetics of hypodontia. 7 Dent Res 1974;53:781-5.

7 Stritzel F, Symons AL, Gage JP. Agenesis of the second premolar in males and females: distribution, numbers and sites affected. 7 Clin Pediatr Dent 1990;15:39-41.

8 Proffitt WR. On the etiology of malocclusion. Br 7 Orthod 1986;13:7.

9 Witkop CJ Jr. Agenesis of succedaneous teeth: an expression of the homozygous state of the gene for the pegged or missing maxillary lateral incisor trait. Am $\mathcal{F}$ Med Gene 1987;26:431-6.

10 Berkowitz BKB, Holland GR, Moxham BJ. A colour atlas and textbook of oral anatomy. London, Wolfe Medical Publications Ltd, 1986:153-67.

11 Johnston MC, Sulik KK. Development of face and oral cavity. In: Bhaskar SN, ed. Orban's oral histology and embryology. 10th ed. St Louis: Mosby, 1986:24-36.

12 Grüneberg $\mathrm{H}$. The genetics of a tooth defect in the mouse Proc $R$ Soc Med 1971;138:437.

13 Thesleff I, Vaahtokari A, Kettunen P. Epithelial-mesenchymal signaling during tooth development. Connect Tissue Res 1995;32:9-15

14 Gorlin RJ, Cohen MM Jr, Levin LS. Syndromes of the head and neck. 3rd ed. Oxford monographs on medical genetics No 19. Oxford: Oxford University Press, 1990:859-77.

15 Gamborg Nielsen P, Sjölund E. Epidermolysis bullos sim plex localisata associated with anodontia, hair and nail disorders: a new syndrome. Acta Derm Venereol (Stockh) 1985;65:526-30.

16 Gamborg Nielsen P. Kallin's syndrome: two more cases. Acta Derm Venereol (Stockh) 1994;74:150-2.

17 Gorlin RJ. Anderson JA. The characteristic dentition of incontinentia pigmenti. F Pediatr 1960;57:78-85

18 Lee CS, Goaz PW. Ectodermal dysplasia: Christ-SiemensTouraine syndrome in a female patient. Gen Dent 1990 38:292-5.

19 Carter WJ, Bordy MD. Ectoderm dysplasia and the Lyon hypothesis. F Dent Child 1967;34:256-8.

20 Freire-Maia N, Pinheiro M. Ectodermal dysplasia. A clinical and genetic study. New York: Alan R Liss, 1984.

21 Garn SM, Lewis AB, Kerewsky RS. Third molar agenesis and size reduction of the remaining teeth. Nature 1963 ; 200:488-9.

22 Stoy PJ. Taurodontism associated with other dental abnormalities. Dent Pract Dent Rec 1960;10:202-5.

23 Mahaney MC, Fujiwara TM, Morgan K. Dental agenesis in the Dariusleut Hitterite Brethren: comparisons to selected Caucasoid population surveys. Am F Phys Anthropol 1990, 82:165-77.

24 Schalk-van der Weide Y, Beemer FA, Faber JA. Symptomatology of patients with oligodontia. $\mathcal{F}$ Oral Rehab 1994;21:247-61.

25 Wright JT. Hair ultrastructure in X-linked ectodermal dysplasia. In: Salinas CF, Opitz JM, Paul NW, eds. Recent advances in ectodermal dysplasias. Birth Defects: Original Article Series 24:2 New York: Alan R Liss 1988: 281-3.

26 Haneke E. Hidrotic ectodermal dysplasias. In: Happle R, Grosshans E, eds. Pediatric dermatology: advances in diag
Grosshans E, eds. Pediatric dermatology: advances in diag-
nosis and treatment. Berlin: Springer-Verlag, 1987:46-54. 27 Thesleff I, Vaahtokari A, Partanen AM. Regulation of 
organogenesis. Common molecular mechanisms regulating the development of teeth and other organs. Int $\mathcal{F}$ Dev Biol 1995;39:35-50.

28 Thesleff I, Sahlberg C. Growth factors as inductive signals regulating tooth morphogenesis. Semin Dev Biol (in press). 29 Lyngstadaas SP, Risnes S, Sproat BS. A synthetic, chemically modified ribozyme eliminates amelogenin, the major translation product in developing mouse enamel in vivo. $E M B O$ $\mathcal{f}$ (in press).
30 Pinheiro $M$, Freire-Maia N. Hair-nail dysplasia: a new pure autosomal dominant ectodermal dysplasia. Clin Genet

31 Gottlieb SK, Fisher BK, Violin GA. Focal dermal hypoplasia: a nine year follow-up study. Arch Dermatol 973.108:551-3.

32 Clarke A, Phillips DI, Brown R, et al. Clinical aspects of $\mathrm{X}$-linked hypohidrotic ectodermal dysplasia. Arch Dis Child 1987;62:989-96. 